\title{
Evaluation of Improved Indoor Environmental Quality during Renovation using the new IV20 Tool
}

\author{
Tine Steen Larsen ${ }^{1}$, Lasse Engelbrecht Rohde ${ }^{2}$, Henrik N. Knudsen ${ }^{3}$, Kim Trangbæk Jønsson², \\ Rasmus Lund Jensen ${ }^{2}$ \\ ${ }^{1}$ tsl@civil.aau.dk, Aalborg University, Department of Civil Engineering, Aalborg, Denmark \\ ${ }^{2}$ Aalborg University, Department of Civil Engineering, Aalborg, Denmark \\ ${ }^{3}$ Aalborg University, Danish Building Research Institute, Copenhagen, Denmark
}

\begin{abstract}
Literature reveals several attempts to evaluate indoor environment (IE) using a single index or indicator. Variations in quality of included measurements and variations in weights between the included areas have challenged the models. The work presented in this paper defines the potential of having a comfortable and healthy IE. It filters out the uncertainty caused by the occupants by looking only at the physical frames given through the building. The occupants are instead included in the evaluation by questionnaires. The case presented shows how it is possible to identify possible IE improvements before a renovation and illustrates how this can be combined with the use of questionnaires.
\end{abstract}

\section{Introduction}

Today, there is a common understanding about the importance and effects of a comfortable and healthy indoor environment in our buildings between building professionals and researchers within the field. Several projects identify and document the benefits of this (MacNaughton et al., 2017; Mendell et al., 2002; Wargocki, Wyon, Sundell, Clausen, \& Fanger, 2000), and the good news are often reported by newspapers and television to the general public.

Even though the focus on this area is growing, indoor environmental quality (IEQ) is still an intangible subject for the main part of the users in today's buildings. They seem to maintain a lack of understanding of the importance of simple actions such as venting, shading and controlling their own IEQ (Andersen, Toftum, Andersen, \& Olesen, 2009; Frontczak, Andersen, \& Wargocki, 2012). On top of this, IEQ is often neglected or downgraded when design decisions are made since most decisions in building design focus on energy savings based on quantitative parameters which often leave the more qualitative parameters, such as IEQ, out of the decisions (Abdul Hamid, Farsäter, Wahlström, \& Wallentén, 2018).

The question now is how to increase the focus on IEQ and generate a demand for better solutions. This question was raised in the REBUS project (Renovating Buildings Sustainably) (REBUS, 2016), which targets deep renovations in the social housing sector. Behind the project is a dedicated partnership representing all parts of the value chain ranging from end users (tenants and social housing companies) through project developers and manufacturers to knowledge institutions. The REBUS project is carried out in a Danish context and has an overall target for the renovations initiated by the project to have a minimum of $50 \%$ energy saving, $30 \%$ reduction of resources and $20 \%$ increment in productivity. One part of this project was to develop tools or methods to increase focus on IEQ in the renovation process. Tools or methods targeted developers, designers, building owners (in this case social housing companies) and occupants/tenants.

REBUS has a broad target group and one solution will not fit all for this case. However, the development of a tool and a strategy that can increase focus on IEQ is a shared goal for all stakeholders. As a result, clear communication about IEQ topics became a priority, and it was decided that the result should be comparable to the scale known from Energy Performance Certifications, which are well known for most people today. This decision was made well aware of the fact that earlier attempts to make a clear single index for IEQ had difficulties. Humphreys concluded in 2005 that this kind of indexes were highly dependent on the weightings between parameters, which would vary between nationalities, building types and even within one parameter alone (e.g. thermal comfort) (Humphreys, 2005). A literature review made by Heinzerling et al. compares the results of weightings between acoustics, indoor air quality (IAQ), lightning and thermal comfort from six different studies in office buildings. None of these results agree with each other and the review showed very large differences in weightings between the different studies (Heinzerling, Schiavon, Webster, \& Arens, 2013).

The amount of IEQ indexes proposed for dwellings are very few. A study by Lai et al was made under subtropical conditions and here temperatures seems to overrule most other parameters when reaching a certain level (Lai, Mui, Wong, \& Law, 2009). Again, this may be climate-specific and could differ between climates.

Despite the difficulties, the experiences and conclusion of earlier works created the foundation for the decisions made in the current project. The aim was to increase demands for, and priority of, IEQ during decision making for renovation projects. This paper will introduce the developed tools followed by a case showing the results for IEQ before and after renovation of a social housing multi storey dwelling. The tool was developed for multi storey dwellings, but shows potential for further development for other building types. 


\section{The tools}

Two new tools, IV20 and a questionnaire-survey-package (QSP), for evaluation of IEQ in dwellings were developed through the partnership project REBUS (Knudsen, Heebøll, Clausen, \& Bekö, 2017; Knudsen \& Larsen, 2018; Larsen et al., 2017; REBUS, 2016). Figure 1 illustrates the idea behind IV20 and the QSP.

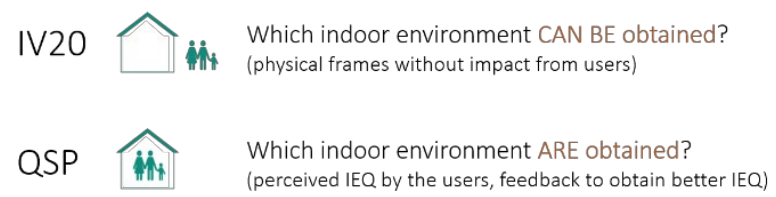

Figure 1: Definition of content in IV20 and the questionnaire-survey-package (QSP).

The following sections describe the main concepts and ideas behind the tools.

\section{IV20}

The IV20 tool is developed for use in the early design phase of new buildings or before renovation of existing buildings. The aim of the tool is to increase focus on IE at a very early stage of the design where key issues important to the later on realized IE are locked. A key parameter for the development of the tool was to leave out all kinds of physical measurements of IE. This decision was due to 1.) leaving out the uncertainty of occupant behaviour by only considering the building alone and 2.) IE measurements are not possible at the stages where the tool will be applied. Thereby the IV20 tool identifies the potential of having a comfortable and healthy Indoor Environment (IE) in a building based on the physical frames setup by the building. The perceived IEQ including the occupant behaviour is evaluated by the QSP (see next section).

IV20 evaluates the potential indoor environment (IE) separately for air quality (IAQ), thermal IE (THER), visual IE (VIS) and acoustic IE (ACO). The tool then weighs the four individual scores into a single value, the Indoor Environmental Quality, communicated by a letter as we know from e.g. Building Energy Performance Certificates. The four evaluation areas are presently weighted equally with $25 \%$ for each. This decision is made based on experiences from earlier work, which found large case to case deviations and lack of data, in order to establish the weights in a reliable matter (Heinzerling et al., 2013; Humphreys, 2005; Ncube \& Riffat, 2012). The authors are confident that deviations between these weightings will exist between different building typologies (e.g. light in offices will be evaluated much differently from light and direct sunlight in private homes), but still do not have sufficient data to convincingly distinguish between weights.

The IV20 evaluation is based on building geometry, data regarding constructions and visual inspection, which are entered into the tool. All analyses and calculations are integrated into IV20. Based on lessons learned from earlier studies and attempts to define a single index (Heinzerling et al., 2013; Humphreys, 2005), IV20 stands out from earlier tools by complementing the overall index with scores for each of the four individual evaluation areas (ACO, IAQ, THER, VIS). By showing each area separately, occupants are able evaluate their future home choosing from the parameters, which are of the greatest importance to them. Table 1 lists the evaluation areas and attached parameters. The parameters included in the tool were identified based on a thorough analysis on an extensive amount of IE parameters, which defined a gross list of parameters (Larsen et al., 2017). Scores of importance for health and comfort respectively were given to each parameter on the gross list by an expert panel. Based on this scoring, 12 traditional IE parameters were identified out of 16 parameters in total for the tool. Evaluation of these were later further detailed into 1-6 criterias for each parameter. The last four parameters (parameter \#4 for each area) considers the users' possibilities of adjusting their own IE. This is included since the possibility for users to adjust their IE positively affects the satisfaction with the experienced IE (Yun, 2018).

Table 1: Evaluation areas, parameters and weights included in IV20.

\begin{tabular}{|c|c|c|c|c|}
\hline & Acoustic IE & Air Quality & Thermal IE & Visual IE \\
\hline $\begin{array}{l}\# \\
\mathbf{1}\end{array}$ & $\begin{array}{c}\text { Absence of } \\
\text { noise from } \\
\text { surroundings } \\
\quad(35 \%)\end{array}$ & $\begin{array}{l}\text { Impact from } \\
\text { outdoor air } \\
(15 \%)\end{array}$ & $\begin{array}{c}\text { Temperature, } \\
\text { summer } \\
(30 \%)\end{array}$ & $\begin{array}{c}\text { Daylight } \\
(35 \%)\end{array}$ \\
\hline $\begin{array}{l}\# \\
2\end{array}$ & $\begin{array}{l}\text { Absence of } \\
\text { noise from } \\
\text { neighbors } \\
(35 \%)\end{array}$ & $\begin{array}{l}\text { Impact from } \\
\text { building and } \\
\text { materials } \\
(35 \%)\end{array}$ & $\begin{array}{c}\text { Temperature, } \\
\text { winter } \\
(25 \%)\end{array}$ & $\begin{array}{c}\text { Direct } \\
\text { sunlight } \\
(25 \%)\end{array}$ \\
\hline $\begin{array}{l}\# \\
\mathbf{3}\end{array}$ & $\begin{array}{l}\text { Absence of } \\
\text { noise in own } \\
\text { dwelling } \\
(25 \%)\end{array}$ & $\begin{array}{l}\text { Impact from } \\
\text { activities (in } \\
\text { dwelling) } \\
(30 \%)\end{array}$ & $\begin{array}{c}\text { Absence of } \\
\text { draft } \\
(20 \%)\end{array}$ & $\begin{array}{c}\text { View out, } \\
\text { view in, solar } \\
\text { shading } \\
(30 \%)\end{array}$ \\
\hline $\begin{array}{l}\# \\
4\end{array}$ & $\begin{array}{c}\text { User } \\
\text { possibilities } \\
\text { to adjust own } \\
\text { IE } \\
(5 \%) \\
\end{array}$ & $\begin{array}{c}\text { User } \\
\text { possibilities } \\
\text { to adjust own } \\
\text { IE } \\
(20 \%)\end{array}$ & $\begin{array}{c}\text { User } \\
\text { possibilities } \\
\text { to adjust own } \\
\text { IE } \\
(25 \%) \\
\end{array}$ & $\begin{array}{c}\text { User } \\
\text { possibilities } \\
\text { to adjust own } \\
\text { IE } \\
(10 \%) \\
\end{array}$ \\
\hline
\end{tabular}

As mentioned, IV20 applies both for new buildings and for existing buildings to be renovated. In renovation, IV20 shows the current IE state of the dwelling to the residents before renovation, and from the scores it identifies where the dwelling has the largest potential for improvements in IEQ. Based on the selected solutions for renovation, a new IV20 calculation is made showing the final result and the improvements realized by the renovation. The framework of the current version of IV20 for apartments is developed with an intension of further development into other building typologies (e.g. single family homes, offices, schools). In order to do this, the existing parameters need to be adjusted (eg. "reverberation times" under "Acoustics" will not be evaluated in the same way for schools) but it is the intension to keep the same overall parameters only adjusting the scoring in relation the each new building typology. 
IV20 is developed for the early design process to help designers and building owners to implement solutions improving IEQ at an early stage. At this stage, the impact on the design is highest since many solutions improving the IEQ often exist in the construction itself and are hard and expensive to apply at a later stage of the building process. IV20 facilitates illustration of the interconnectivity between different design solutions and their impact on the IE parameters by dynamic updates in the IE compass, which shows all parameters included in IV20 (explained further in Figure 3 and the accompanying text). The IE Compass is communication directed towards the designers, with information on the score for all parameters included in IV20.

A different communication level is used for occupants, that only shows the overall score and the separate scores for air quality, thermal IE, visual IE and acoustic IE.

\section{Questionnaire Survey Package}

The Questionnaire Survey Package is intended to be used in parallel with the IV20 tool to evaluate the perceived IEQ in social housing before and after renovation (Knudsen et al., 2017). The package includes a questionnaire and a distribution procedure of the questionnaire to the tenants to ensure the highest possible response rate. The intention is to use the questionnaire before the renovation in order to identify the initially most pronounced IEQ problems, thus allowing for targeted problem solving adding most value for the tenants. The questionnaire also evaluate tenants' satisfaction and symptoms related to the IEQ. After the renovation, the questionnaire may be applied to document whether or not the defined goals for the indoor environment have been reached.

\section{The apartment test case}

The apartment used for illustration of IV20 is situated in Aalborg in the northern part of Denmark. The apartment is on the first floor in a 2-storey apartment building. The apartment has five rooms, a kitchen, a bathroom and a lavatory. The gross area is $111 \mathrm{~m}^{2}$, the net area $92 \mathrm{~m}^{2}$. Figure 2 shows a floor plan of the apartment.

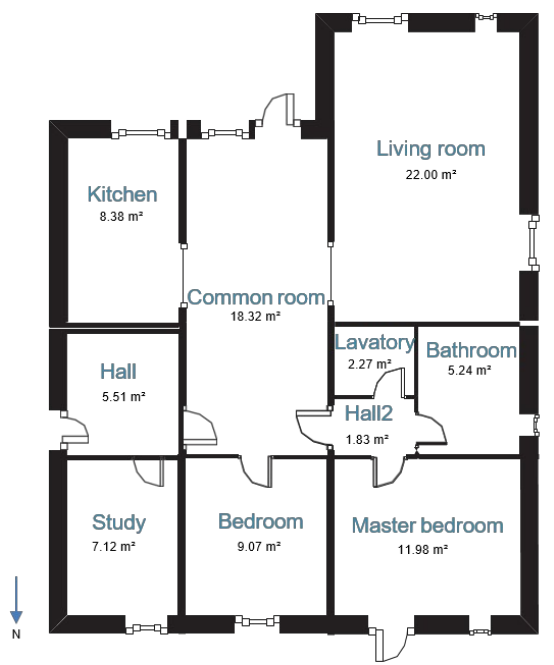

Figure 2: Floor plan of the registered apartment.
The focus for renovation was improving ventilation, facades and windows in order to reduce the energy consumption. IV20 was not developed when this renovation was planned, and the IEQ only had a minor focus during the design process. Before renovation, the apartment had a hybrid ventilation solution with mechanical exhaust from the lavatory and bathroom and inlet of fresh air through vents in the windows. After renovation, this was changed to balanced mechanical ventilation with heat recovery and preheating of air. Although interior parts of the apartment were changed, this is not taken into consideration here since these solutions only affected the IV20 evaluation to a minor extent. For instance, no acoustic improvements were made, which could have improved the IEQ score. Table 2 shows the major changes made during the renovation.

Table 2: Changes applied during renovation of the apartment.

\begin{tabular}{|c|c|c|}
\hline & $\begin{array}{c}\text { Before } \\
\text { renovation }\end{array}$ & After renovation \\
\hline Ventilation & $\begin{array}{c}\text { Hybrid with } \\
\text { mechanical } \\
\text { exhaust in } \\
\text { bathroom and } \\
\text { lavatory, } \\
\text { ACR } 0.21 / \mathrm{s} \text { per } \\
\mathrm{m}^{2} \text {, } \\
\text { no heat recovery }\end{array}$ & $\begin{array}{c}\text { Mechanical, } \\
\text { balanced, } \\
\text { ACR } 0.3 \mathrm{l} / \mathrm{s} \text { per } \\
\mathrm{m}^{2} \text {, } \\
\text { heat recovery }\end{array}$ \\
\hline $\begin{array}{c}\text { U-value } \\
\text { external walls }\end{array}$ & $0.4 \mathrm{~W} / \mathrm{m}^{2} \mathrm{~K}$ & $0.16 \mathrm{~W} / \mathrm{m}^{2} \mathrm{~K}$ \\
\hline $\begin{array}{l}\text { U-value } \\
\text { windows }\end{array}$ & $1.5 \mathrm{~W} / \mathrm{m}^{2} \mathrm{~K}$ & $0.52 \mathrm{~W} / \mathrm{m}^{2} \mathrm{~K}$ \\
\hline $\begin{array}{c}\text { g-value } \\
\text { windows }\end{array}$ & 0.63 & 0.53 \\
\hline $\begin{array}{l}\text { LT-value } \\
\text { windows }\end{array}$ & 0.7 & 0.74 \\
\hline
\end{tabular}

\section{Results}

The results are calculated using the IV20_beta version. Minor adjustments may be applied in the final version, but the overall setup is finished, and the results shown in this section are still considered reliable. The results section is divided into one section describing IV20 "before renovation" and another section describing "after renovation". This is followed by an example of using the QSP.

\section{IV20 Before renovation}

An IV20 calculation was carried out for the existing conditions in the apartment. Figure 3 shows the result of this in the IE Compass developed for building designers and consultants.

The IE Compass before renovation reveals a large need for IE improvements. Acoustics has the lowest potential with $49 \%$ but also acoustics is the hardest evaluation area to improve in a renovation since most conditions are defined by the construction. However, ACO1.1 concerned with external noise depends on the external wall and 


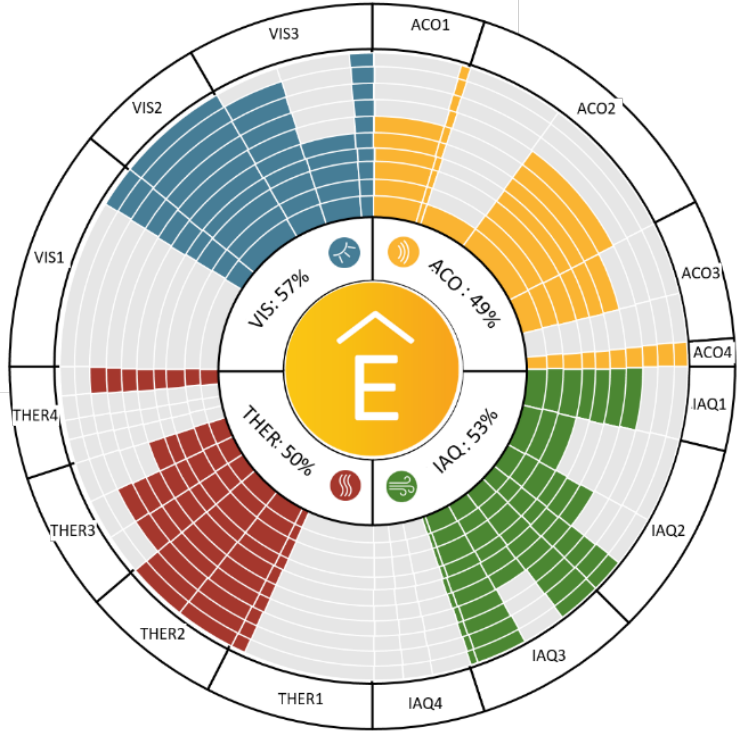

Figure 3: IE Compass before renovation of the apartment. Criteria numbers according to Table 1.

windows, which were changed later on during the renovation. ACO2.1 considers airborne noise from neighbours, which is much harder to change, especially in this renovation where focus was on facades. ACO3.2 considers reverberation time in the dwelling. Also, here the score is low $(0 \%)$, corresponding to long reverberation time and acoustic discomfort, another parameter that is difficult to influence in the present renovation.

IAQ reached $53 \%$. For IAQ, the low scores are found in IAQ1 due to no filtering of the outdoor air (the apartment was naturally ventilated). Natural ventilation and the resulting low air change rates (ACR) give low scores in IAQ2.2. In IAQ3.2, the type of exhaust hood in the kitchen causes the low score, and for IAQ4 the lack of possibilities for the user to increase the ACR causes the low score.

The potential thermal IEQ (50\%) before renovation reveals possible problems due to high temperatures during summer without shading possibilities in THER1.1. In THER3.1, the low score is caused by the natural ventilation, which might cause draft during winter, and in THER4 the lack of possibilities to increase the ACR, and thereby decrease the high temperatures during summer, are again causing a low score.

VIS obtains $57 \%$ and here the low score is caused by VIS1.1 and a low amount of daylight caused by deep room with small windows. Also, VIS3.2 gives a low score due to high risk of annoyance from persons looking in from outside the dwelling.

Together with the IE Compass, which is targeting the designers and building owners, IV20 generates a scorecard that is easily read for the occupants. Figure 4 shows the scorecard before renovation. Here the overall score for the Indoor Environmental Quality before renovation is $\mathrm{E}$. The overall score is shown together with the score for each evaluation area. Only visual IE obtains a $\mathrm{D}$, the rest gets an E. Thereby great potential for improvements are identified within each of the four evaluation parameters.

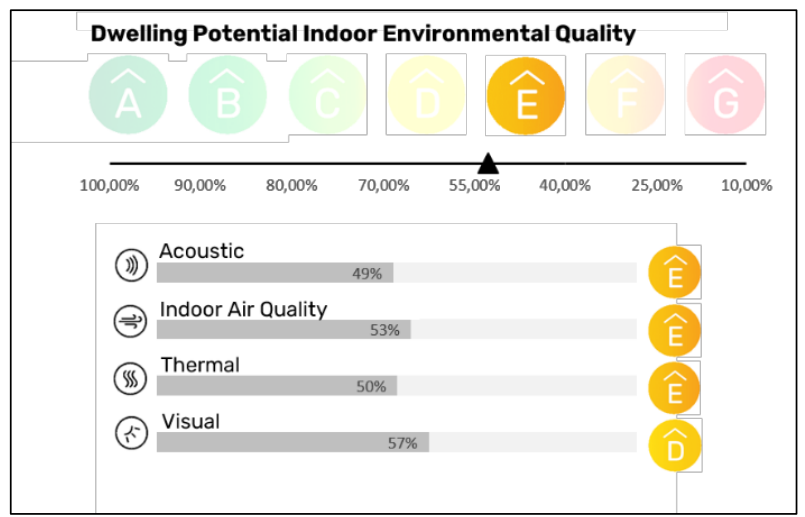

Figure 4: Scorecard for the apartment before renovation.

\section{IV20 after renovation}

IV20 is applied during the design process for estimations of how different design solutions will affect the IEQ. Figure 5 shows the IE Compass for the case apartment with the changes carried out during renovation implemented into the Compass.

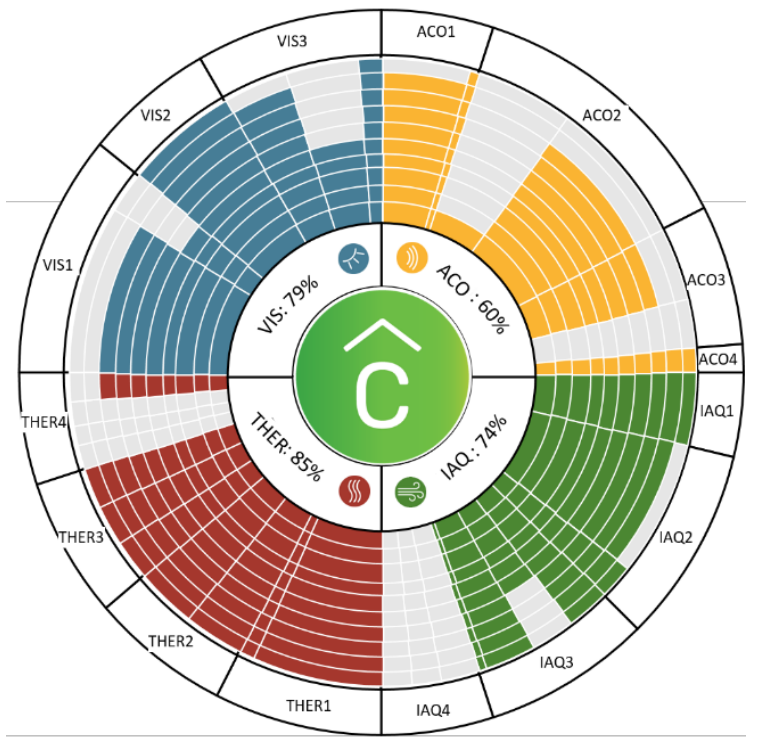

Figure 5: IE Compass after renovation of the apartment. Criteria numbers according to Table 1.

To improve the IEQ in the apartment after renovation, focus is on the areas with low potential IEQ in the IE Compass, in Figure 3. Low scores were obtained for all of the evaluation areas, but some parameters within each area were lower than others. Solutions for improvements need to be considered and also linked to the price of the change/improvement since some improvements will be very expensive (e.g. improved acoustics due to air borne noise from neighbours) compared to others (e.g. improved U-values, where the demand energy savings were the driver). 
The only improvement in acoustics is found in ACO1.1 where new windows and external walls are the cause for the improvement. A new construction was made during renovation corresponding to a construction standard as new buildings. Figure 6 shows the building before, during and after renovation. No other acoustic improvements were included in the renovation mainly due to cost and lack of focus on these parameters. The change in acoustics was from $50 \%$ before renovation up to $60 \%$ after renovation.

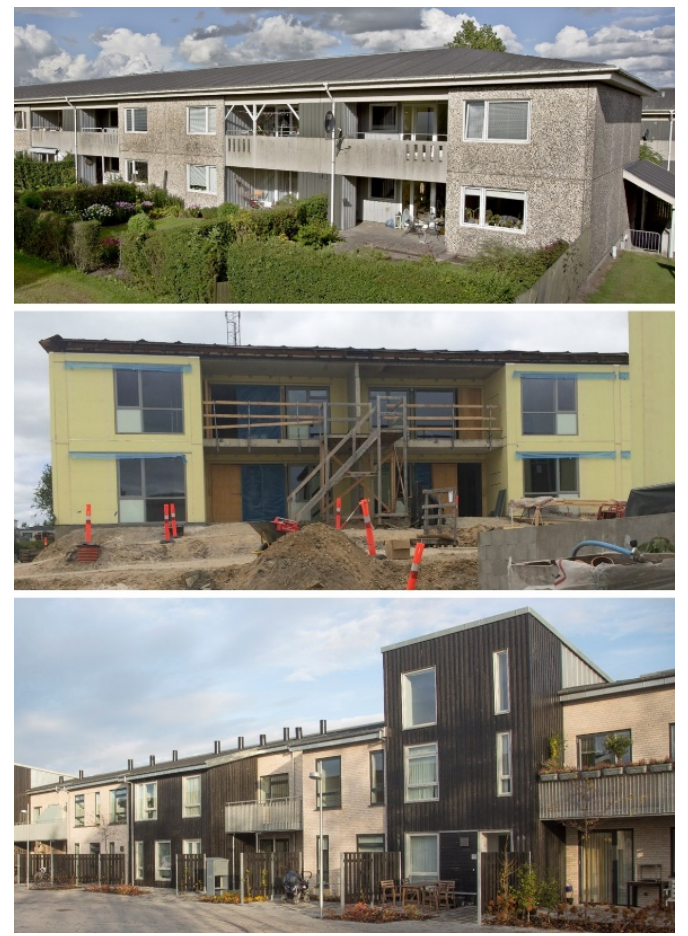

Figure 6: The case building before, during and after renovation.

The IAQ score changed from $53 \%$ to $74 \%$ after renovating. The biggest contribution lies in the changed ventilation strategy changing to mechanical ventilation, which improved both IAQ1 due to filtering of ventilation air and IAQ2 due to improved air change rates (ACR). The type of exhaust from the kitchen was not changed, and therefore the score on this parameter did not change/improve. The score in IAQ4 is still $0 \%$ and was not changed during the renovation.

A great challenge for the thermal IE before renovation was high temperatures during summer. This was handled by lowering the g-value, which, in combination with the increased ACR, improved the score in THER1.1 and thereby a much more comfortable IE during warm summer days. The new windows, well-insulated facades and mechanical ventilation improved THER3 to maximum points by eliminating problems with leaky joints, cold downdraught and draft from ventilation. THER4 remains unchanged. The overall score for thermal IEQ is raised from $50 \%$ to $85 \%$ after the renovation.

Before renovation, the visual IE was poor due to deep rooms and small windows. After renovation, the window area is slightly increased, which has a positive influence on the score in VIS. The overall score improves from 57\% to $79 \%$. The greatest change is found in VIS1.1, which evaluates the amount of daylight. Here, the score increases from $0 \%$ to $80 \%$ just within this parameter. In the parameters for visual IE under VIS3, some parameters will often be fixed before and after a renovation. This goes for the "view out" (VIS3.1) which most often not is changed during renovation. Also, the "view in" (VIS3.2) can be difficult to influence in the case with neighbouring block of apartments located just in front of the apartment. The overall score for the Indoor Environmental Quality is after renovation calculated to $\mathrm{C}$, with the largest improvement found for thermal IE improving from $\mathrm{E}$ to B. As expected, the smallest improvement was within acoustic IE only changing from E to D. Figure 7 shows the IV20 scorecard for the apartment after renovation.

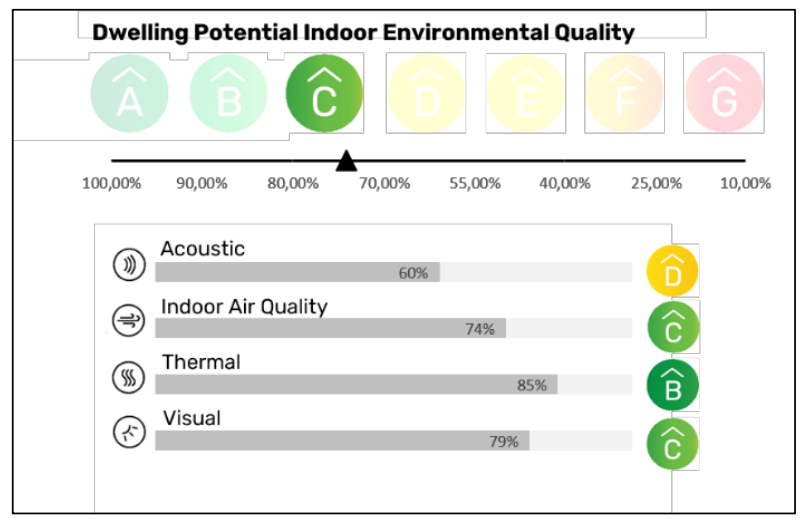

Figure 7: Scorecard for the apartment after renovation.

\section{The Questionnaire-Survey-Package}

As an example of the results obtained from using a similar questionnaire in another case study (Knudsen \& Jensen, 2015), Figure 8 shows the percentages of tenants who have problems with different aspects of the indoor environmental parameters before and after renovation. It reveals problems with the temperature being too cold, noise from the outside and too little daylight before renovation. Based on this finding, it would have been possible to design solutions, which in a targeted manner solved the specific problems. Figure 8 shows that after renovation the identified problems were actually significantly reduced. The percentage of tenants who had problems with the temperature being too cold decreased from $58 \%$ to only $5 \%$ after the renovation. Likewise, the percentage of tenants who had problems with noise from the outside and too little daylight decreased from $44 \%$ and $33 \%$ before to only $5 \%$ and $2 \%$, respectively, after the renovation. As an interesting unforeseen exception, more tenants $(35 \%)$ experienced problems with noise from technical installations (mainly the ventilation system according to comments) after the renovation compared to only $9 \%$ before the renovation. This underlines the need for a holistic approach when renovating existing buildings, so that solving one problem does not introduce other problems. Overall, the questionnaire survey revealed that problems with the various indoor environment aspects of the different parameters were reduced after the renovation. 


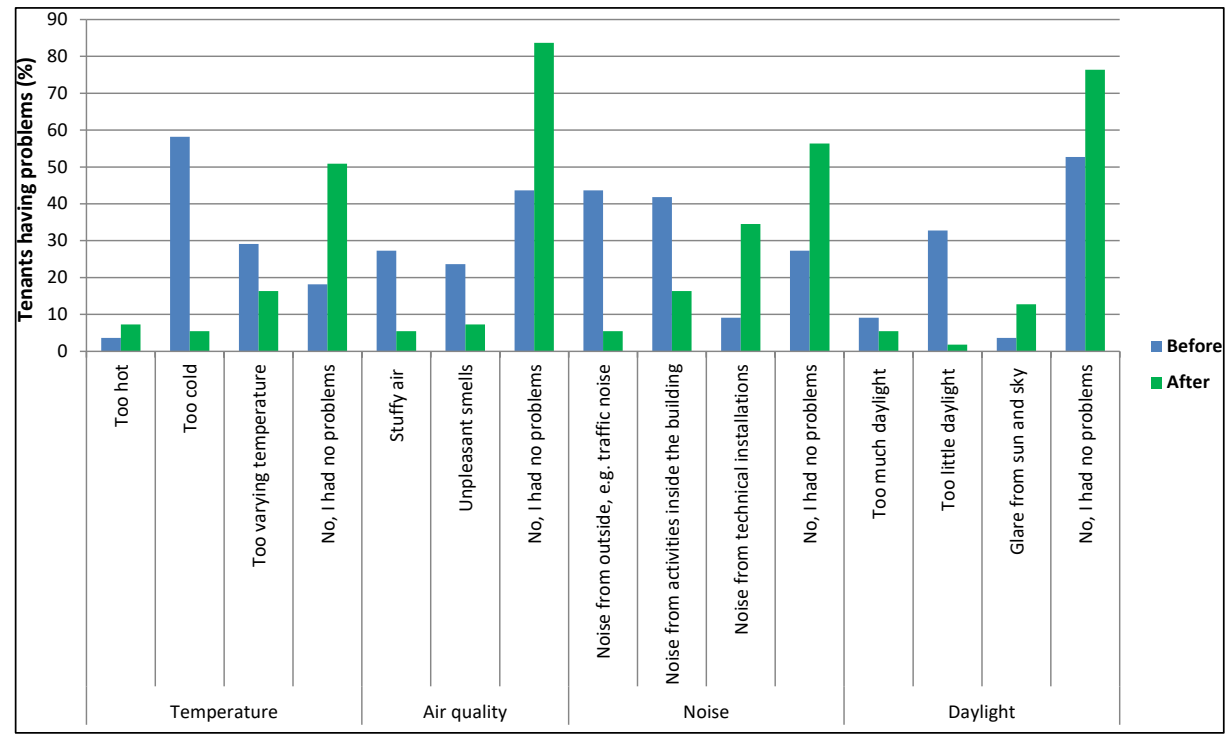

Figure 8: The percentage of tenants who have problems with different aspects of the indoor environment parameters before and after the renovation work.

Figure 9 shows the percentage of tenants satisfied with the IE parameters temperature, draught, air quality, noise and daylight and the IE as a whole before and after the renovation. For all the parameters, the number of satisfied tenants increased markedly. For the perceived indoor environment as a whole, the number of tenants who were satisfied rose from $17 \%$ before to $91 \%$ after the renovation.

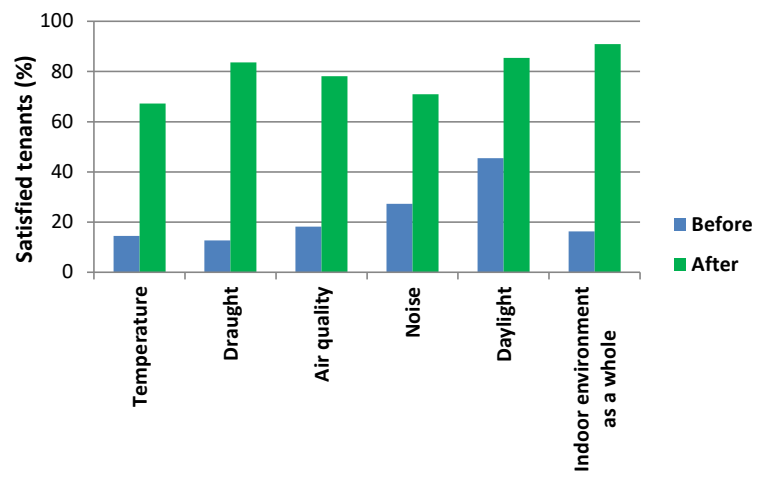

Figure 9: The percentage of tenants satisfied with the different indoor environment parameters and the indoor environment as a whole before and after the renovation work.

\section{Discussion}

During this project, the holistic nature of the IV20 tool and the combination of IAQ, thermal, acoustic and visual IE into a single parameter showing the combined IEQ potential for dwellings have positively affected the prioritization and realization of IE in the case presented. The tool clearly connects design solutions with their influence on the IE for all stakeholders (designers/ architects/engineers) during the early design process where the most important decisions are made. The authors are well aware that earlier work on combining all parameters into one index have had challenges (e.g. Heinzerling et al., 2013; Humphreys, 2005; Ncube \& Riffat, 2012a; Residovic, 2017) with deviating weights as one of the results. However, IV20 considers the potential of obtaining a comfortable and healthy IE based purely on the physical framework setup by the building. Thereby, it leaves out the uncertainty that follows from the residents and their behavior, which will vary significantly between dwellings.

As illustrated through the case in this paper, the use of IV20 together with the QSP complements each other very well. IV20 identifies the potential for improvements in the physical conditions of apartments while the QSP identifies the problems experienced by the occupants. The QSP can be used to strengthen the findings from IV20 for some large-scale projects, although the cost of carrying out QSP's is high compared to the three to four hours needed to make an IV20 evaluation. At the same time, the engine behind IV20 calculates the detailed information necessary for designers and consultants to carry out their work and help them include IE at an earlier state in the design phase, than it is the case today.

As mentioned before, the authors see the combination of IAQ, thermal, acoustic and visual IE into one parameter as one of the major assets of IV20. Both due to the evaluation method itself but also due to the strong and simple communication with a well-known single-letter indicator made familiar by the Energy Performance Certificates. Today, the optimization for energy savings in our buildings is very well handled and well integrated into our mindset during design. The market is now ready for increased focus on comfort and health centered in our indoor environment. Furthermore, an overall European target is to increase the rate of renovations, and the authors see IV20 as a contribution to reach this target by 
visualizing the value of comfortable and healthy IE and thereby creating a demand for improvements through renovation.

\section{Conclusion}

Today IEQ is often neglected or rated with low priority when design decisions are made. Most decisions in a renovation project focus on energy savings based on quantitative parameters, neglecting the qualitative parameters, such as IEQ. This leaves IEQ of the early, and very important, first decisions regarding design. A design, which will greatly influence the realized IE in the dwelling. The results from this paper conclude, that IEQ can be included in the early decisions regarding renovation in a more tangible way, through clear communication of the results with a single letter and four letters/bars for each evaluation area presented to the residents, who decides whether to renovate or not. When the decision for renovation is made, IV20 will guide the designer on what to renovate by showing the potential for improvements and the potential effect of different solutions.

IV20 has a great potential within the design phase, where the tool immediately shows changes in the design regarding IEQ and their interactions with other parameters. Several combinations of solutions will help improve the IEQ and if combined with cost, it can be used as an after-renovation value for money indicator.

Furthermore, it is concluded, that IV20 results combined with the questionnaire-survey-package gives a more robust baseline for decisions. The combination of the tools evaluates the potential IEQ and includes occupant perception-based issues to be addressed during renovation not found by looking at the potential IEQ (e.g. smell of tobacco smoke between apartments).

\section{Acknowledgement}

The work presented in this paper was made possible by the support of the dedicated partnership REBUS Renovating Buildings Sustainably. The partnership is funded by The Innovation Foundation Denmark, Realdania and The Landowners' Investment Foundation (in Danish Grundejernes Investeringsfond).

\section{References}

Abdul Hamid, A., Farsäter, K., Wahlström, Å., \& Wallentén, P. (2018). Literature review on renovation of multifamily buildings in temperate climate conditions. Energy and Buildings, 172, 414-431. https://doi.org/10.1016/J.ENBUILD.2018.04.032

Andersen, R. V., Toftum, J., Andersen, K. K., \& Olesen, B. W. (2009). Survey of occupant behaviour and control of indoor environment in Danish dwellings. Energy and Buildings, 41(1), 1116. https://doi.org/10.1016/j.enbuild.2008.07.004

Frontczak, M., Andersen, R. V., \& Wargocki, P. (2012). Questionnaire survey on factors influencing comfort with indoor environmental quality in Danish housing. Building and Environment, 50, 56-
64. https://doi.org/10.1016/j.buildenv.2011.10.012

Heinzerling, D., Schiavon, S., Webster, T., \& Arens, E. (2013). Indoor environmental quality assessment models: A literature review and a proposed weighting and classification scheme. Building and Environment, $\quad 70, \quad 210-222$. https://doi.org/10.1016/j.buildenv.2013.08.027

Humphreys, M. A. (2005). Quantifying occupant comfort: are combined indices of the indoor environment practicable? Building Research \& Information, 33(4), 317-325. https://doi.org/10.1080/09613210500161950

Knudsen, H. N., Heebøll, A., Clausen, G., \& Bekö, G. (2017). Perceived indoor environment: Questionnaire for evaluation before and after renovation. (In Danish: Oplevet indeklima Spørgeskema til evaluering før og efter renovering). REBUS samfundspartnerskab.

Knudsen, H. N., \& Jensen, O. M. (2015). SBI 2015:28 - Tenants' experiences and satisfaction with renovated and energy retrofitted social housing. Statens Byggeforskningsinstitut.

Knudsen, H. N., \& Larsen, T. S. (2018). Evaluation of the Perceived Indoor Environment before and after Renovation of Social Housing. In Conference proceedings: Indoor Air 2018: The 15th Conference of the International Society of Indoor Air Quality \& Climate (ISIAQ), July 22 to 27, 2018, Philadelphia, PA, USA (p. 8). ISIAQ. Retrieved from http://vbn.aau.dk/da/publications/evaluationof-the-perceived-indoor-environment-before-andafter-renovation-of-social-housing(f329bbf5-329f4e93-a96b-3eeb7dd0a24b).html

Lai, A. C. ., Mui, K. W., Wong, L. T., \& Law, L. Y. (2009). An evaluation model for indoor environmental quality (IEQ) acceptance in residential buildings. Energy and Buildings, 41, 930-936. Retrieved from https://ac-els-cdncom.zorac.aub.aau.dk/S0378778809000723/1s2.0-S0378778809000723main.pdf? tid=546390f2-35c5-4136-bca6f6d87b3bc5 f0\&acdnat $=1548762604 \_0623 a 380 \mathrm{e} 5 \mathrm{e}$ 1c4280944192de2d4cfd8

Larsen, T. S., Clausen, G., Bekö, G., Heebøll, A., Witterseh, T., Hellgren, E., ... Mortensen, L. H. (2017). Central Parameters for characterization of Indoor Environment of Buildings (In Danish: Centrale parametre til karakterisering af bygningers indeklima). REBUS samfundspartnerskab.

MacNaughton, P., Satish, U., Laurent, J. G. C., Flanigan, S., Vallarino, J., Coull, B., ... Allen, J. G. (2017). The impact of working in a green certified building on cognitive function and health. Building and Environment, 114, 178-186. https://doi.org/10.1016/J.BUILDENV.2016.11.041

Mendell, M. J., Fisk, W. J., Kreiss, K., Levin, H., Alexander, D., Cain, W. S., ... Wallingford, K. M. (2002). Improving the Health of Workers in Indoor 
Environments: Priority Research Needs for a National Occupational Research Agenda. American Journal of Public Health, 92(9), 1430-1440. https://doi.org/10.2105/AJPH.92.9.1430

Ncube, M., \& Riffat, S. (2012). Developing an indoor environment quality tool for assessment of mechanically ventilated office buildings in the UK - A preliminary study. Building and Environment, 53 , 26-33 https://doi.org/10.1016/J.BUILDENV.2012.01.003

REBUS. REBUS - Renovating Buildings Sustainably 2016-2020 (2016). Further project information see http://rebus.nu/

Residovic, C. (2017). The New NABERS Indoor Environment tool - the Next Frontier for Australian
Buildings. Procedia Engineering, 180, 303-310. https://doi.org/10.1016/J.PROENG.2017.04.189

Wargocki, P., Wyon, D. P., Sundell, J., Clausen, G., \& Fanger, P. O. (2000). The Effects of Outdoor Air Supply Rate in an Office on Perceived Air Quality, Sick Building Syndrome (SBS) Symptoms and Productivity. Indoor Air, 10(4), 222-236. https://doi.org/10.1034/j.16000668.2000.010004222.x

Yun, G. Y. (2018). Influences of perceived control on thermal comfort and energy use in buildings. Energy and Buildings, 158, 822-830. https://doi.org/10.1016/j.enbuild.2017.10.044 